\title{
Neurochemical Theory of Epilepsy Pathogenesis in It's Neurological and Mental Manifestations
}

\author{
Alexander Kharibegashvili \\ Telavi District Hospital, Telavi State University, Telavi, Georgia \\ Email address: \\ unitelavi@rambler.ru

\section{To cite this article:} \\ Alexander Kharibegashvili. Neurochemical Theory of Epilepsy Pathogenesis in It's Neurological and Mental Manifestations. American \\ Journal of Psychiatry and Neuroscience. Vol. 8, No. 2, 2020, pp. 33-39. doi: 10.11648/j.ajpn.20200802.13
}

Received: April 23, 2020; Accepted: June 12, 2020; Published: July 4, 2020

\begin{abstract}
In the article, in light of the hypothesis about the pathogenesis of epilepsy the author considers certain clinical manifestations of epilepsy, touches upon the neurochemistry of behavior, as well as neurotransmitter hypothesis of schizophrenia. According to the hypothesis, in epileptic patients, epileptogenic substances are permanently accumulating in the brain, which in the course of epileptic activity in the brain undergo metabolic changes requiring their removal from the organism. When the concentration of epileptogenic substances in the brain reaches a threshold value, they cause a seizure, and in lower concentrations, they cause epileptic activity typical for the interictal period. In the context of this hypothesis, there are discussed the clinical signs of epilepsy such as forced normalization, reinforcement epilepsy activity during the sleep deprivation and one of the paradoxical effect of antiepileptic drugs such as phenomen when antiepileptic drugs prescribed cause an improvement of the electroencephalographic image but the clinical deterioration and increasing frequency of seizures, and the change of antiepileptic drugs give us the opposite results: improvement of the clinical picture and the deterioration of the electroencephalographic image. According to the supplemented hypothesis, epileptogenic substances, except that, during epileptic activity in the brain undergo metabolic transformations necessary for their removal from the body; there are also alternative transformation neurochemical pathways necessary for their further removal (elimination) from the organism. The hypothesis discusses the modern principles of epilepsy treatment. It was proposed to call the phenomenon "clinicalelectroencephalographic dissociation" when the anti-epileptic drugs are associated with the improved electroencephalographic pattern, but with the deterioration of the clinic and frequent seizures, and the drug change leads to the opposite-the improvement of the clinical picture and the EEG deterioration. Forced normalization is considered as one of the manifestations of epilepsy aggravation and "clinical-electroencephalographic dissociation". When reviewing biological antagonism of schizophrenia and epilepsy the author suggests a hypothesis that if an area of the brain producing epileptogenic substances and an area of the brain producing endogenic psychogenic substances causing psychopathology coexist simultaneously, then, in the event of a generalized convulsive seizure involving the brain in full, epileptogenic as well as psychogenic substances are released. At the same time epilepsy is demonstrated, while schizophrenia is not. The same could be the mechanism of therapeutic activity (effect) of electroconvulsive therapy.
\end{abstract}

Keywords: Epilepsy, Neuro Mediators, Forced Normalization of Electroencephalogram Image, Aggravation, Hypothesis, Biological Antagonism of Schizophrenia and Epilepsy, Behavior

\section{Introduction}

The history of studies on epilepsy counts many centuries, vast banks of clinical and physiological data has accumulated, paradigms related to etiology and pathogenes is changed. However, a general theory combining and explaining these data has not been developed yet. Researchers of various profiles keep suggesting new theories and hypothesis striving to interpret various demonstrations of epilepsy, to unite them in a single concept. [1,2].

According to the current conception neurochemical mechanisms, disturbances associated with disorders of ionic, mediatorial and energetic processes leading to increased membrane penetration and resulting enhanced depolarization of neurons, their hyperexcitation, neuronal epileptisation, 
hypersynchronization, formation of epileptic focus and ultimately an epileptic system, play significant role in initiation of epileptic activity [3, 4], which in the event of antiepileptic system (consisting of caudate nucleus, cerebellum, lateral hypothalamic nuclei, caudal pontine reticular nucleus) failure leads to development of epilepsy as a disease. Participation of hormonal and immune system in pathogenic process has been established and studies are still ongoing. [3-6].

Attention of researchers has recently been attracted by channelopathies - pathologic changes in channels of $\mathrm{K}+$ and $\mathrm{Na}+$ - receptors which make it impossible to maintain normal gradient of ion concentration on both sides of the membrane and condition paroxysmal depolarization of membranes. These defective sodium channels remain open too long resulting in neuronal hyperexcitation [7].

Two types of channelopathy are known: genetic, during which ion channel function is abnormal or absent as a result of mutation (genetic channelopathy is the major cause for idiopathic generalized form of epilepsy), and autoimmune channelopathy, when antibodies disrupt channel function. Recent studies have provided growing evidence for the existence of a third type - ranscriptional channelopathies resulting from changes in the expression of non-mutated channel genes [8].

Opioid neuropeptidergic system has significant influence as well as peptides produced by it - enkephalins, endorphins etc., functioning as neurotransmitters $[9,10]$.

Glutamatergic system plays important role in induction of epilepsy including in itself NMDA-receptor ionotropic glutamate receptor, selectively binding $\mathrm{N}$ methyl-D-aspartate (NMDA) and neurotransmitter glutamate. Glutamate is the basic neurotransmitter for excitatory synapses in the brain. Synapses which use glutamate as a transmitter are up to approximately $50 \%$ localized in neurons of central nervous system. The largest quantity of them can be found in telencephalon and hippocampus [11]. In physiological conditions NMDAreceptors are activated at millimolar concentrations of glutamate present in synaptic cleft for several milliseconds. [12].

During pathological activation receptors are activated at micromolar concentrations but for a significantly longer period of time [13]. As a result $\mathrm{Ca}^{2+}$ concentrations are increased in cells and $\mathrm{K}+$ ions are accumulated in extracellular space. Neuron saturation with calcium ions serves as trigger for mobilization of ions from intracellular $\operatorname{depot}[14,15]$.

Increased concentration of extracellular $\mathrm{K}+$ are viewed as one of the major mechanisms for neurons involvement in epileptic process by many authors.

Another possible mechanism includes mutations, resulting in ineffective activities of gamma-aminobutyric acid (GABA) (most widespread inhibitory neurotransmitter of the brain). Epilepsy associated with mutations in genes of some nonionic channels has also been revealed [16].

\section{Neurochemical Theory of Epilepsy}

\subsection{Hypothesis}

A hypothesis is suggested [17] in relation with metabolic mechanisms of pathogenesis of epilepsy in respect of which several clinical manifestations of epilepsy were reviewed, among them the phenomenon of forced normalization of electroencephalogram image (EEG) [18]. A hypothesis has been developed [17], according to which epileptogenic substances are constantly accumulating in the brain of an epileptic patient and when reaching the threshold value cause a seizure. In addition, epileptogenic substances during epileptic activity in the brain undergo metabolic transformations required for their removal from the body. If the concentration of epileptogenic substances in the brain fails to reach the threshold value, they cause weak epileptic activity mostly reflected in epileptic bioelectric phenomenon, typical for EEG pattern of interictal period. Moreover, certain parts of epileptogenic substances apparently 'drive out' interictal epileptic activity of the brain (part of epileptogenic substances is released during interictal epileptic activity).

\subsection{Certain Clinical Manifestations of Epilepsy}

The authors have reviewed the following clinical manifestations of epilepsy from the perspective of the given hypothesis.

Cases when prescription of anti-epileptic drugs is associated with improved electroencephalographic pattern, but with the deterioration of the clinic and frequent seizures, are observed in practice of epileptologists $[19,20]$. The drug change leads to the opposite result - improvement of the clinical picture and the EEG deterioration.

According to the hypothesis, the given clinical manifestation of epilepsy may be explained as follows. In the course of interictal epileptic activity of the brain parts of epileptogenic substances are released, as a result of which the threshold concentration of the given biogenic amines is slowly accumulated and reaches the maximal value within a longer period of time. Thus time intervals between seizures grow in proportion with the intensity of epileptic activity of the brain during interictal period. By prescribing certain antiseizure medications it may be achieved that cell neurons will not be responsible for epileptic activity at sub-threshold concentration of epileptogenic substances, however, the seizure will still develop if the concentration of epileptogenic substances reaches the threshold value. In such case, in terms of absence of epileptogenic substance release through epileptic activity of the brain during interictal period their accumulation up to the threshold value will be faster, seizures will develop more frequently, however interictal EEG pattern will improve.

In case of appropriate ("successful") selection of antiseizure drugs if improvement of EEG pattern including its normalization (known as forced normalization of EEG) as well as improvement of clinical condition including total elimination seizures is achieved, the patient often experiences 
psychogenic discomfort to the extent when in order to get rid of it he/she stops administration of medications thus provoking a seizure $[18,21-23]$.

When explaining the given fact by forced normalization of EEG it should be noted that anti-seizure drugs are selected so that neurons are exhausted (or blocked) and stop responding by epileptic activity at the threshold as well as sub-threshold value of epileptogenic substance concentrations. The given biogenic amine saccumulate in the brain, which is manifested in psychoneurological disorders. However the seizure provoked by the patient himself/herself removes epileptic substances which improves mental health of the patient.

It is also common knowledge that during physiological sleep epileptic bioelectric phenomenon is much more frequently revealed. Sleep deprivation leads to emersion of epileptic bioelectric phenomen while waking, and in case of presence of the latter - to increase of their frequency. Prolonged deprivation may provoke a seizure. [2, 3, 24-26].

As for the above mentioned clinical manifestation of epilepsy, according to the hypothesis, sleep deprivation is more likely to lead to a quicker accumulation of epileptogenic substances as they are not eliminated through increased epileptic activity during sleep. High concentration of epileptogenic substances leads to increased epileptic activity while waking. And prolonged sleep deprivation leads to accumulation of epileptogenic substances up to the threshold value thus provoking a seizure.

\subsection{Supplement to the Hypothesis}

However, the proposed hypothesis does not explain the whole spectrum of contemporary principles for treating epilepsy, according to which by subscribing anti-epileptic drugs cessation of epileptic bioelectric phenomena and normalization of EEG, as well as cessation of seizures are achieved, and anti-epileptic drugs are usually discontinued after two years upon cessation of seizures and normalization of EEG. [3, 27].

An supplementation to the given hypothesis was proposed later [28]. According to this supplementation, epileptogenic substances, in addition to undergoing metabolic transformations required for their further removal from the body during epileptic activity in the brain, also have alternative neurochemical metabolic pathways of transformation required for their further elimination from the body.

When epilepsy responds to contemporary treatment principles alternative neurochemical pathways of metabolism of epileptogenic substances required for their further elimination from the body are activated. This additional chain of neurochemical transformation may be activated spontaneously when certain concentrations of epileptogenic substances are reached in the brain (this mechanism may function under normal conditions, simultaneously preventing occurrence of epileptic seizure at increased concentrations of epileptogenic substances in the brain), but at the same time this chain may be activated under the influence of antiepileptic drugs.
In case of presence of a certain biochemical defect causing absence of alternative pathways of metabolism of epileptogenic substances the phenomenon of forced normalization may be observed, as well as the above described phenomenon, observed during epilepsy treatment, when prescription of anti-epileptic drugs is accompanied by improvement of EEG pattern but deterioration of clinical condition and increased frequency of seizures, while changes in the prescribed drugs lead to a reversed effect improvement of clinical condition and deterioration of EEG pattern, also the phenomenon of activation of epileptic activity by deprivation of sleep up to development of epileptic seizure.

Authors believe it would be reasonable to name the phenomenon when prescription of anti-epileptic drugs is accompanied by improvement of EEG pattern but deterioration of clinical condition and increased frequency of seizures, while changes in the prescribed drugs lead to a reversed effect as "clinical-electroencephalographic dissociation".

While reviewing forced normalization and aggravation of epilepsy as a result of anti-epileptic drugs administration in connection with each other, it should be noted that in the overwhelming majority of cases of epilepsy aggravation normalization of EEG is not observed [18], while in case of forced normalization deterioration of the patient's condition is noted, which is evidenced by the fact that patients, unaware of forced normalization of EEG, often discontinue administration of anticonvulsants and provoke seizure in order to "improve" their condition.

From this perspective it is possible to agree with the authors [18] regarding forced normalization being one of the demonstration of epilepsy aggravation. In addition, this phenomenon may be viewed as "clinical-encephalographic dissociation" as improvements in electroencephalography (EEG) and deterioration of clinical picture may be observed.

In the present article, in light of the above hypothesis the author additionally considers certain clinical manifestations of epilepsy in psychiatry, among them the theory on biological antagonism of schizophrenia and epilepsy, touches upon the neurochemistry of behavior, as well as neurotransmitter hypothesis of schizophrenia, including dopamine theory of schizophrenia, and draws parallels with the given theory and the hypothesis he proposes.

Considering the significance of neurotransmitters, as well as endogenic psychogenic substances enhancing or inhibiting neurotransmitters production or their impact, attempts of applying the given hypothesis are feasible for explain other forms of normal or pathological brain activity.

\subsection{Certain Mental Manifestations of Epilepsy}

Epilepsy is characterized by neurological as well as mental clinical manifestations. Consider certain mental manifestations of epilepsy.

Regarding ambulatory automatism and other psychic epileptiform paroxysms, a multitude of data given in relevant literature links behavior (both, inborn and acquired - learnt) 
with neurotransmitters. Various neurotransmitter theories have been developed which explain different pathologies of behavior, psychic disorders, including schizophrenia, by excess number of certain transmitters or deficiency of others [29]. Dopamine hypothesis is dominant among these theories. [30].

The author supports neurotransmitter hypothesis.

Inborn behavior derived from simple unconditioned reflexes to complex instincts (such as migration of birds in autumn to warm countries, returning of fish from oceans to rivers for spawning, striving of newborn turtles towards the sea); acquired behavior based on a complex of interrelated unconditioned and conditioned reflexes with temporary connections and neuronal nets, chains and ensembles taking part in these forms of behaviors (both inborn and acquired), are connected to certain neurons [31, 32]. While these neurons in their turn, function through certain excitatory or inhibitory neurotransmitters. Therefore, it is not surprising that rising or falling levels of certain excitatory or inhibitory neurotransmitters, their disbalance, lead to disorders various types of behavior.

It is interesting to review deprived behavior [31, 32]. If any given behavior is deprived, neurotransmitters responsible for the given behavior are accumulated, as they (neurotransmitters) are not consumed in the process of the given behavior. When concentration level for the given neurotransmitter reaches certain threshold, forced manifestation of this behavior occurs, sometimes in distorted manner: being alone a person starts to speak to himself/herself, in case of sleep deprivation, one may see dreams while awake, during sex deprivation sex may be manifested perversely.

Thus according to the hypothesis suggested by us epileptiform psychic paroxysms, such as ambulatory automatism, clouded state, epileptic psychosis, are developed in the event of accumulation of certain neurotransmitters, stimulating certain neurons responsible for certain behavior, to the threshold values, after which epileptiform psychic paroxysm is developed during the course of which epileptogenic and psychogenic substances (epileptogenic substances may simultaneously serve as such (psychogenic)) undergo metabolic changes necessary for their further elimination from the body.

In this regard EEG examination of all psychic pathologies accompanied by paroxysms during the paroxysms as well as the inter-paroxysmal period is actual.

EEG examination results [33] reveal increase in B-activity during multiple (numerous) psychic diseases, while Bactivity, as we know, is activated during cogitativity. It is interesting, that brain activity in patients with severe forms of schizophrenia resembles to the clinical pattern characteristic to people taking strong psychostimulants and amphetamine. In such case, if we presume that intensification of certain cogitative and other psychic processes are linked to increased production of certain excitatory neurotransmitters, then increase in production of these neurotransmitters will distort the given cogitative or psychic activity (causing "plus" symptoms such as delirium and hallucination). Lowering the level of excitatory or increasing the level of inhibitory neurotransmitters will initiate the appearance of "minus" symptoms.

Natural science is familiar with drawing analogies between multiple similar events as well as similarity between development mechanisms of these events.

This brings the proposition, that certain endogenic toxic psychogenic substances may also accumulate during nonepileptiform psychic paroxysms, among them autoimmune antibodies (a large majority of mental diseases, including schizophrenia, has endogenic character), which may themselves have neurotransmitter function or induce growth in production of certain neurotransmitters. When reaching specific threshold, they cause psychic paroxysm (nonepileptiform), during which psychogenic substances undergo metabolic transformation, necessary for their further eliminations from the body, but at the same time the EEG image will not reveal patterns characteristic to epilepsy. Therapeutic benefits of plasmapheresis during psychic diseases favors the existence of possible toxic endogenic psychotic substances (including autoimmune antibodies) [34].

Moreover, it is possible, that similar mechanisms of pathogenesis are in action during paroxysms of nonpsychotic nature too (other than psychiatric part of medicine, such as general medicine) where other chemical substances, different from neurotransmitters, reach threshold value, for example, during hypertonic crisis - the substances increasing blood pressure, and which undergo metabolic changes required for their further elimination during this paroxysm.

Therapeutic benefits of sleep in treatment of Delirium Tremens are well-known [35]. The facts that during Delirium Tremens epileptic syndrome is often developed, while EEG imaging of epileptic patterns become more frequent during sleep, attracts the attention. Metabolic changes in neurotransmitters or endogenic psychogenic substances required for the elimination in the process of epileptiform, as well as non-epileptiform brain activity may enhance during sleep.

Kindling-effect $[36,37]$ is noteworthy the essence of which is that frequent subthreshold stimulation increases convulsive readiness and may lead to spontaneous convulsions in previously healthy experimental animal.

Kindling may play important role in secondary epileptic syndromes (more often it may be a pathogenic element specifically in epileptic syndromes - secondary epilepsy) where primary focus of the disease, such as tumor, stroke, may play the role of subthreshold stimulators and provoke convulsive seizures as well as epileptiform mental paroxysms, reducing the activity threshold (concentration threshold) of epileptogenic substances.

Similarly, we may think that pathological focuses in the brain resulting from own irritant activity may decrease the activity threshold of endogenic psychogenic substances in pathogenesis of development of non-epileptiform psychic paroxysms, and promote development of secondary mental pathologies in neuropsychiatry [38]. 


\subsection{Epilepsy and Shizophrenia}

Biological antagonism of schizophrenia and epilepsy is identified [39]. In the event of presence of generalized epileptic seizures, characterized with seizures with loss of consciousness and tonic-clonic seizures of extremities (limbs) the brain is fully involved in the epileptic activity. In such case, if there is an area of brain producing epileptogenic substances and an area generating an excess of behavioral neurotransmitter, surfeit of which leads to psychopathology, then during convulsive seizures transformation and elimination of both neurotransmitters occurs, whereupon epilepsy is manifested and schizophrenia is not as during the seizures apart of neurotransmitters causing convulsive seizures abundance of neurotransmitters resulting in psychopathology are also released, and their levels (neurotransmitters resulting in psychopathology) fail to reach the level causing pathology of psyche. With convulsive therapy of schizophrenia, a similar process of transformation and elimination of neurotransmitters of behavior may take place.

When reviewing the possible association between epilepsy and schizophrenia G. Huber [40] wrote: "There is not a single symptom or syndrome of schizophrenia which is not met in patients with epilepsy, but this rule does not work counterwise." This may be explained by the fact that pathological process during schizophrenia touches upon only the areas of brain responsible for emotional and cognitive functions, while epileptic process, epileptization of neurons apart from these areas, may affect any functional group of neurons.

Regarding dopamine theory of schizophrenia [29-32], dopamine increases general activity and reactivity of the brain in a majority of brain neurotransmitters. Knowing the association between dopaminergic system with seven other neurotransmitter systems, it cannot be excluded that association to other neurotransmitter systems will be discovered in future. This is why neuroleptic agents decrease general activity of the brain, which is linked to multiple side effects and manifestation of neuroleptic agents, including general retardation of patients. It may be presumed that treatment of mental diseases will further develop towards searching a more selective neurotransmitters and their antagonists. As it is commonly known, polymorphism of schizophrenia forced E. Bleuler to interpret it as a group of related diseases. This is why it cannot be excluded that in the event of various forms of schizophrenia various neurotransmitters play the leading role in the development of pathology.

\section{Discussion}

When giving neurochemical explanation to the above mechanism of seizure occurrence, it has to be noted that according to available literature absolute or relative (in comparison with inhibitory neurotransmitter) increase of excitatory transmitters in the neurons of the brain at the preconvulsive stage of seizureis revealed $[3,4,41]$. We believe, that occurrence of epileptic seizures is conditioned by spontaneous local or generalized instability of membranes of cortical neurons resulting from inherited or acquired particularities of metabolic processes: disbalance of excitatory and inhibitory neurotransmitters. In the process of functioning of neurons, the potential of their membranes simultaneously (synchronously) alters. In the event of channelopathies with lower threshold of neuronal excitability, epileptic seizures may occur at much lower concentrations of epileptogenic substances. It may be assumed that further development of neurochemistry and neuroimmunology of epilepsy will provide opportunities to classify epileptic seizures based on as to increase of which excitatory transmitters or decrease of which inhibitory transmitters cause the disbalance as a result of which neurons in the process of epileptic activity "are forced to get rid of increased level of excitatory transmitters". In this regard all substances need to be considered (and primarily the ones acting as neurotransmitters of the brain: aminoacids, kinurenine, serotonin, dopamine, agonists of gamma-aminobutyric acid receptors [23] etc.) increase in absolute or relative levels of which directly or indirectly give rise to sodium-potassium pump activity impairment, increased penetrability of membranes, increased tendency towards depolarization and consequently hyperexcitability of membranes. By analogy, it is necessary to find out which disbalance of which neurotransmitters leads to particular psychopathology, and all the processes leading to this disbalance.

\section{Conclusion}

Development of Neurotransmitter theories is a major achievement in contemporary psychiatry. Completely new role of more and more neurotransmitters in mental disorders schizophrenia and depression - is being identified. On the basis of the above developments new medicinal preparations- neuroleptics and antidepressants are being created.

It is advisable to accelerate such developments -studying the role of neurotransmitters - in the field of epileptology.

However, it should be noted that neurotransmitter link represents an intermediary link in neurochemical chain, which is preceded by other links (stages), the activities of which result in neurotransmitter link, which in its turn, precedes another links of chain. Apart of neurotrnsmitter link, from the perspectives of development of psychiatry we may presume that more attention will be given to studying links of neurochemical chain of pathogenesis which precede the neurotransmitter link, so as to eliminate development of pathology at an earlier stage.

It is interesting to study the impact of biological treatment methods on neurotransmitter balance and metabolism in psychiatry.

All methods for studying brain neurochemistry, both noninvasive and invasive, can be mobilized. Microdialysis of the brain can give a lot.

Proposed assumptions and hypothesis require serious 
experimental studies, good experimental capability and in case of their verification new paradigms, theories, new approaches to treatment of epilepsy and mental diseases with conservative as well as surgical methods may emerge.

\section{References}

[1] Gabashvili V. M. // Sb. Trudov Tbilisskogo simpoziuma po funktsional'noy neyrokhirurgii. - Tbilisi, 1985. - S. 5-10.

[2] Saradzhishvili P. M., Geladze T. SH. Epilepsiya. - M., 1977.- S. 65-102.

[3] Karlov V. A. Epilepsiya. - M., 1990. — S. 71-115.

[4] Marc A., Dichter M. D. Emerging Concepts in the Pathogenesis of Epilepsy and Epileptogenesis //Arch. Neurol. -2009.-66 (4).-443-447.

[5] Lipatova L. V. Neyroimmunnyye mekhanizmy epilepsii kak klyuch $\mathrm{k}$ patogeneticheskomu lecheniyu zabolevaniy // Epilepsiya.-2010.-№3.-S. 20-27.

[6] Page B. Pennell. Hormonal Aspects of Epilepsy //Neurologic Clinics.-2009.-V. 27, Is. 4.-P. 941-965.

[7] Belousova E. D. Trudnosti differentsial'noy diagnostiki epilepsii // Rossiyskiy vestnik perinatologii i pediatrii. -2006.№6. S. 13.

[8] Stephen G. Waxman Transcriptional channelopathies: An emerging class of disorders //Nature Reviews Neuroscience. -2001.-2.-P. 652-659.

[9] Joseph G. Bajorek, Randall J. Lee, Peter Lomax. Neuropeptides: A role as endogenous mediators or modulators of epileptic phenomena //Annals of Neurology._-1984._-Vol. 16.-P. 31-38.

[10] Koide S. Et al. Metabolic profile of opioid peptides differs in the hippocampus and striatum of seizure-susceptible E1 mice //Neurochem. Res.-1995.-Vol. 20.-P. 279.

[11] Astrid G. Chapman Glutamat and epilepsy //J. Nutr.-April 1, 2000.-Vol. 130, № 4.-P. 1043-1045.

[12] Clements J. D., Lester R. A., Tong G. Et al. The time course of glutamate in the synaptic cleft //Science.-1992.-Vol. 258, № 5087.-P. 1498-1501.

[13] Globus M. Y., Busto R., Dietrich W. D. Et al. Effect of ischemia on the in vivo release of striatal dopamine, glutamate, and gammaaminobutyric acid studied by intracerebral microdialysis //J. Neurochem.—1988.—Vol. 51, № 5.-P. 1455-1464.

[14] Frandsen A., Schousboe A. Mobilization of dantrolenesensitive intracellular calcium pools is involved in the cytotoxicity induced by quisqualate and $\mathrm{N}$-methyl-D-aspartate but not by 2-amino-3-(3-hydroxy-5-methylisoxazol-4-yl) propionate and kainate in cultured cerebral cortical neurons //Proc. Natl. Acad. Sci. USA.—1992.—Vol. 89, № 7.-P. 2590-2594.

[15] LeiS. Z., Zhang D., Abele A. E., Lipton S. A. Blockade of NMDA receptor-mediated mobilization of intracellular $\mathrm{Ca}^{2+}$ prevents neurotoxicity //Brain. Res.—1992.—Vol. 598, № 12.-P. 196-202.
[16] Litovchenko T. A. Epilepsiya: terminologiya, epidemiologiya, klassifikatsiya, etiologiya, patogenez //NeyroNews. - 2010.№ 2.-S. 27-33.

[17] Kharibegashvili A. S., Chachiya G. I. K voprosu o patogeneze epilepsii // Mezhdunarodnyy nevrologicheskiy zhurnal. 2012. — № 6 (52).- S. 167-173.

[18] Mukhin K. YU., Pylayeva O. A. Problema aggravatsii epilepticheskikh pristupov na fone terapii antiepilepticheskimi preparatami // Russkaya pochta detskoy nevrologii. — 2014. — №2 (T. IX).— S. 27-33.

[19] Jacqueline A. French. Seizure Exacerbation by Anitiepileptic Drugs //Epilepsy Curr._2005._5 (5).-192-193.

[20] Lai Choo Ong. Seizures exacerbated by antiepileptic drugs in children //Neurology Asia.—2010.—15 (Suppl. 1).-P. 11-12.

[21] Siddhartha Nadkarni, Vanessa Arnedo, Orrin Devinsky. Psychosis in epilepsy patients //Epilepsia.-2007.-Vol. 48, Issue (Suppl. 9).-P. 17-19.

[22] Krishnamoorthy E. S., Trimble M. R. Forsed Normalization: Clinical and Therapeutic Relevance //Epilepsia._1999.—40 (Suppl. IO).-P. 57-64.

[23] Pylayeva O. A., Mukhin K. YU., Petrukhin A. S. Pobochnyye effekty antiepilepticheskoy terapii. - M.: Granat, 2016.

[24] Beth A. Malow. Sleep Deprivation and Epilepsy //Epilepsy Curr.-2004.-4 (5).-P. 193-195.

[25] Yevtushenko S. K., Omel'yanenko A. A. Klinicheskaya elektroentsefalografiya u detey. - Donetsk: Donechchina, 2005. - 860s.

[26] Yevtushenko S. K., Omel'yanenko A. A. Idiopaticheskiye generalizovannyye epilepsii // Mezhdunarodnyy nevrologicheskiy zhurnal. — 2011. — №6 (44).- S. 56-72.

[27] Litovchenko T. A. Sovremennyye printsipy farmakoterapii epilepsii //NeyroNEWS.—2010.—№5 (24).-S. 32-37.

[28] Kharibegashvili A. S. Yevtushenko S. K.. Ivanova M. F. O vozmozhnykh novykh neyrokhimicheskikh mekhanizmakh patogeneza epilepsii. // Mezhdunarodnyy nevrologicheskiy zhurnal. -2017.-№2 (88). - S. 11-15.

[29] Matthysse S., Sugarman J. Neurotransmitter Theories of Shizophrenia, Handbook of Psychopharmacology, Volume 10, Neuroleptics and Schizophrenia P. 221-242.

[30] Gründer G., Dopamine Hypothesis of Schizophrenia The Neurobiology of Schizophrenia Book.2016, Pages 109-124, Chapter 7.

[31] Clark M. R., Grunstein M. The role of neurotransmitters in human behavior. Are We Hardwired?: The Roles of Genes in Human Behavior P 148-171 Print publication date; 2004 Print ISBN-13; 9780195178005 Published to Oxford Scholarship Online 2010.

[32] Choudhury A., Sahu T. Et al., Neurochemicals, Behaviours and Psychiatric Perspectives of Neurological Diseases Neuropsychiatry (London) (2018) 8 (1) P 396-424.

[33] Veyn A. M. Patogenez tserebral'nykh paroksizmal'nykh sostoyaniy. Plenum Vsesoyuznogo obshchestva nevropatologov i nauchnogo soveta po nevrologii. Materialy. Kiyev. 1991; 12. 
[34] Gough J. L, Coebergh J., Chandra B., Nilforooshan R. Electroconvulsive therapy and /or plasmapheresis in autoimmune encephalitis? World Journal of Clinical Cases (WJCC) August 16, 2016|Volume4|Issue8| P 223-238.

[35] Brower Kirk J., Alcohol's Effects on Sleep in Alcoholics, Alcohol Res Health. 2001; 25 (2): P 110-125.

[36] Cain D. P. Excitatory neurotransmitters in kindling: excitatory amino acid, cholinergic, and opiate mechanisms. NeurosciBiobehav Rev. 1989 Winter; 13 (4): 269-76.

[37] McNamara JO. Role of neurotransmitters in seizure mechanisms in the kindling model of epilepsy. FedProc. 1984 Jul; 43 (10): 2516-20.

[38] Helmstaedter C., Witt J-A. Chapter 10 - Behavioral and neuropsychological aspects of frontal and temporal lobe epilepsy, The Neuropsychiatry of Epilepsy edited by Michael Trimble, Bettina Schmitz Cambridge University Press 2002 P 90-108.

[39] Avedisova A. S. Svyaz' mezhdu shizofreniyey i epilepsiyey: istoriya voprosa i sovremennoye sostoyaniye problemy. Zhurnal: Zhurnal nevrologii i psikhiatrii im. S. S Korsakova. 2016; 116 (9): 126-132.

[40] Huber G, Gross G. The bridges between Neurology and Psychiatry. Neurol Croat. 2003: 52 (suppl2): 65-7.

[41] Gubanova N. B., Karakulova YU. V. Patogeneticheskoye znacheniye serotoninergicheskikh proyavleniy $\mathrm{V}$ razvitii idiopaticheskikh generalizovannykh form epilepsii // Byulleten' sibirskoy meditsiny. -2008.-№5.-S. 87-89. 